\title{
Response to Antiretroviral Therapy after a Single, Peripartum Dose of Nevirapine
}

\section{Citation}

Lockman, Shahin, Roger L. Shapiro, Laura M. Smeaton, Carolyn Wester, Ibou Thior, Lisa Stevens, Fatima Chand, et al. 2007. "Response to Antiretroviral Therapy after a Single, Peripartum Dose of Nevirapine." N Engl J Med 356 (2) (January 11): 135-147. doi:10.1056/nejmoa062876.

\section{Published Version}

doi:10.1056/NEJMoa062876

\section{Permanent link}

http://nrs.harvard.edu/urn-3:HUL.InstRepos:26835361

\section{Terms of Use}

This article was downloaded from Harvard University's DASH repository, and is made available under the terms and conditions applicable to Other Posted Material, as set forth at http:// nrs.harvard.edu/urn-3:HUL.InstRepos:dash.current.terms-of-use\#LAA

\section{Share Your Story}

The Harvard community has made this article openly available.

Please share how this access benefits you. Submit a story.

Accessibility 
ORIGINAL ARTICLE

\section{Response to Antiretroviral Therapy after a Single, Peripartum Dose of Nevirapine}

\author{
Shahin Lockman, M.D., Roger L. Shapiro, M.D., M.P.H., Laura M. Smeaton, M.S., \\ Carolyn Wester, M.D., Ibou Thior, M.D., Lisa Stevens, M.D., Fatima Chand, M.S., \\ Joseph Makhema, M.B., Ch.B., M.R.C.P., Claire Moffat, M.B., Ch.B., M.P.H., \\ Aida Asmelash, M.D., M.P.H., Patrick Ndase, M.B., Ch.B., M.P.H., \\ Peter Arimi, M.B., Ch.B., Erik van Widenfelt, B.S., Loeto Mazhani, M.D., \\ Vladimir Novitsky, M.D., Ph.D., Stephen Lagakos, Ph.D., and Max Essex, D.V.M., Ph.D.
}

\section{A BSTRACT}

BACKGROUND

A single dose of nevirapine during labor reduces perinatal transmission of human immunodeficiency virus type 1 (HIV-1) but often leads to viral nevirapine resistance mutations in mothers and infants.

\section{METHODS}

We studied the response to nevirapine-based antiretroviral treatment among women and infants who had previously been randomly assigned to a single, peripartum dose of nevirapine or placebo in a trial in Botswana involving the prevention of the transmission of HIV-1 from mother to child. All women were treated with antenatal zidovudine. The primary end point for mothers and infants was virologic failure by the 6-month visit after initiation of antiretroviral treatment, estimated within groups by the Kaplan-Meier method.

RESULTS

Of 218 women who started antiretroviral treatment, 112 had received a single dose of nevirapine and 106 had received placebo. By the 6-month visit after the initiation of antiretroviral treatment, $5.0 \%$ of the women who had received placebo had virologic failure, as compared with $18.4 \%$ of those who had received a single dose of nevirapine $(\mathrm{P}=0.002)$. Among 60 women starting antiretroviral treatment within 6 months after receiving placebo or a single dose of nevirapine, no women in the placebo group and $41.7 \%$ in the nevirapine group had virologic failure $(\mathrm{P}<0.001)$. In contrast, virologic failure rates did not differ significantly between the placebo group and the nevirapine group among 158 women starting antiretroviral treatment 6 months or more post partum $(7.8 \%$ and $12.0 \%$, respectively; $\mathrm{P}=0.39)$. Thirty infants also began antiretroviral treatment (15 in the placebo group and 15 in the nevirapine group). Virologic failure by the 6-month visit occurred in significantly more infants who had received a single dose of nevirapine than in infants who had received placebo $(\mathrm{P}<0.001)$. Maternal and infant findings did not change qualitatively by 12 and 24 months after the initiation of antiretroviral treatment.

\section{CONCLUSIONS}

Women who received a single dose of nevirapine to prevent perinatal transmission of HIV-1 had higher rates of virologic failure with subsequent nevirapine-based antiretroviral therapy than did women without previous exposure to nevirapine. However, this applied only when nevirapine-based antiretroviral therapy was initiated within 6 months after receipt of a single, peripartum dose of nevirapine. (ClinicalTrials.gov number, NCT00197587.)
From the Division of Infectious Diseases, Brigham and Women's Hospital (S. Lockman); the Departments of Immunology and Infectious Diseases (S. Lockman, R.L.S., C.W., I.T., L.S., J.M., V.N., M.E.) and Biostatistics (L.M.S., S. Lagakos), Harvard School of Public Health; and the Division of Infectious Diseases, Beth Israel Deaconess Medical Center (R.L.S.) — all in Boston; and Botswana-Harvard School of Public Health AIDS Initiative Partnership for HIV Research and Education (S. Lockman, R.L.S., C.W., I.T., L.S., F.C., J.M., C.M., A.A., P.N., P.A., E.W., V.N., M.E.) and the Botswana Ministry of Health (L.M.) - both in Gaborone, Botswana. Address reprint requests to Dr. Lockman at the Division of Infectious Diseases, Brigham and Women's Hospital, 15 Francis St., PBB-A4, Boston, MA 02115, or at slockman@hsph.harvard.edu.

N Engl J Med 2007;356:135-47. Coppright (๑) 2007 Massachusetts Medical Society. 
$\mathrm{N}$

EVIRAPINE REMAINS CENTRAL TO THE prevention of mother-to-child transmission of human immunodeficiency virus type 1 (HIV-1) and to combination antiretroviral treatment throughout much of the developing world. ${ }^{1,2}$ Nevirapine administered as one dose to the mother and one to the newborn reduces mother-to-child transmission of HIV-1 by 41 to $47 \%,{ }^{3,4}$ and well over 875,000 women and infants have received a single dose of nevirapine. ${ }^{5} \mathrm{~A}$ single dose of nevirapine is the cornerstone of the regimen recommended by the World Health Organization (WHO) to prevent mother-to-child transmission among women without access to antiretroviral treatment and among those not meeting treatment criteria. ${ }^{1}$ However, nevirapine resistance is detected (with the use of standard genotyping techniques) in 20 to $69 \%$ of women ${ }^{6-10}$ and 33 to $87 \%$ of infants ${ }^{11,12}$ after exposure to a single, peripartum dose of nevirapine (less frequently among HIV-infected infants who also received a short course of zidovudine prophylaxis ${ }^{13}$ ). As compared with placebo, a previous single dose of nevirapine was associated with lower rates of virologic suppression to less than 50 copies per milliliter (but was not associated with lower rates of suppression to less than 400 copies per milliliter) on subsequent nevirapine-based antiretroviral treatment in Thailand, although this finding was not associated with the timing of the postpartum initiation of antiretroviral treatment. ${ }^{14}$ To our knowledge, infant response to nevirapine-based antiretroviral treatment after the administration of a single dose of nevirapine has not been described. We conducted a prospective observational study nested within a randomized clinical trial to assess the virologic responses of women and infants to nevirapinebased antiretroviral treatment after previous exposure to a single dose of nevirapine or placebo in the setting of a short course of zidovudine.

METHODS

\section{STUDY POPULATION AND MONITORING}

Between March 2001 and October 2003, a total of 1200 pregnant women in Botswana who were infected with HIV-1 underwent randomization during the Mashi trial of the prevention of motherto-child transmission of HIV-1. ${ }^{10,15}$ We conducted an observational antiretroviral-treatment study within the randomized cohort of the parent Mashi trial. In the Mashi trial, women received a short course of zidovudine from 34 weeks' gestation through delivery, and mother-infant pairs were randomly assigned to receive, double-blinded, a single dose of nevirapine or placebo (one maternal dose at the onset of labor, and one infant dose at 48 to 72 hours after birth). Mothers and their infants were also randomly assigned to either 6 months of breast-feeding with zidovudine prophylaxis for the infants or formula-feeding with 1 month of zidovudine for the infants (zidovudine for the infants was stopped if infants were diagnosed with HIV infection). On August 12, 2002, in response to external data, the Mashi trial was modified to provide a single dose of nevirapine to all infants. ${ }^{10}$

Combination antiretroviral treatment with nevirapine and zidovudine-lamivudine (Combivir, GlaxoSmithKline) was made available to all qualifying participants in the Mashi trial starting in October 2002. Pregnant or postpartum women with CD4+ cell counts of less than 200 cells per cubic millimeter or an acquired immunodeficiency syndrome (AIDS)-defining illness or both qualified for antiretroviral treatment, as did infants infected with HIV-1 who were younger than 12 months, whose percentage of CD4+ lymphocytes (CD4+ percentage) was less than $25 \%$, or who had symptoms related to HIV-1. Nelfinavir, stavudine, and didanosine were available in cases of drug toxicity or virologic failure. The Botswana Health Research Development Committee and the Harvard School of Public Health Human Subjects Committee approved the study. All women provided written informed consent.

All women who consented to participate and who started postpartum nevirapine-based antiretroviral treatment before October 2004 (allowing for at least 9 months of antiretroviral treatment) were included in this analysis. All HIV-infected infants who were born before the Mashi Study was modified in August 2002 and who started nevirapine-based antiretroviral treatment were also included.

Before the initiation of antiretroviral treatment and every 3 months thereafter, mothers and their infants underwent clinical and laboratory monitoring (CD4+ cell count, plasma HIV-1 RNA measurements, hematologic studies, blood chemical studies, and liver-function tests), and education about and assessment of adherence to treatment. Additional monitoring for toxic effects occurred 2 and 4 weeks after the start of antiretroviral treatment. 


\section{MEASUREMENT OF PLASMA HIV-I RNA}

Plasma HIV-1 RNA was assessed with the use of the standard Amplicor HIV-1 Monitor, version 1.5 (Roche Diagnostics), protocol (lower limit of detection, 400 copies per milliliter). The Roche Amplicor HIV-1 Monitor UltraSensitive Method (version 1.5) protocol was used for a subgroup of women who had HIV-1 RNA levels below the lower limit of detection with the standard test.

\section{HIV-I GENOTYPING}

HIV-1 genotyping was performed on plasma samples with the use of the ViroSeq HIV-1 Genotyping System (Celera Diagnostics). Nevirapine resistance was defined by the presence of any of the following mutations: 100I, 103N, 106A/M, 108I, 181C/I, $188 \mathrm{~L} / \mathrm{C} / \mathrm{H}$, or $190 \mathrm{~A}$ (i.e., a score on the resistance scale of more than 50, according to the Stanford University drug-resistance database as of April 2006). ${ }^{16}$ Plasma samples obtained before antiretroviral treatment and at the time of virologic failure for women with virologic failure were tested.

\section{STUDY END POINTS}

The primary study end point for both women and infants was virologic failure by the 6-month visit. Virologic failure was defined as a confirmed plasma HIV-1 RNA level of at least 400 copies per milliliter at or after the 6-month visit after the initiation of antiretroviral treatment, or a drop in the HIV-1 RNA level of less than 1 log at the 3-month visit with a detectable plasma HIV-1 RNA level at 6 months. Secondary end points included virologic failure by 12 and 24 months after the initiation of antiretroviral treatment, virologic failure by early (within 6 months post partum) or late (6 months or more post partum) initiation of antiretroviral treatment, an HIV-1 RNA level of less than 400 copies per milliliter at 6,12 , and 24 months after the initiation of antiretroviral treatment, and time to virologic failure (the rate of virologic failure during the entire follow-up period).

\section{STATISTICAL ANALYSIS}

Pretreatment laboratory-test measurements were obtained within 90 days before the start of antiretroviral treatment. Window periods for visits used the midpoint between consecutively scheduled visits at 3, 6, 12, 18, and 24 months. All mentions of time points after the initiation of antiretroviral treatment refer to the related visit window. We used the Kaplan-Meier method to estimate the rates of virologic failure by the end of the 612-, and 24-month windows for visits for the primary and related secondary end points. Data from women who did not have virologic failure were censored at the time of the last measurement of the plasma HIV-1 RNA level. For analyses comparing viral loads at specific times, we used Fisher's exact test to compare binomial proportions on observed HIV-1 RNA measurements.

To assess whether differences in virologic failure that occurred in recipients of a single dose of nevirapine or placebo varied according to the timing of the initiation of antiretroviral treatment after the single dose, we tested for a statistical interaction, using Cox regression, with time from delivery to the initiation of antiretroviral treatment as a continuous covariate. We also modeled the interaction term by dividing the cohort into prespecified subgroups according to the timing of the initiation of antiretroviral treatment (less than 6 months post partum vs. 6 months or more post partum). When an interaction was detected, separate analyses were performed according to subgroup. We assessed time to virologic failure using the Cox regression model, and we used the log-rank test to compare recipients of a single dose of nevirapine with recipients of placebo. Wilcoxon rank-sum tests were used to compare the distribution of CD4+ cell counts (or changes from baseline) in recipients of a single dose of nevirapine and recipients of placebo at each time point. Analyses are based on all data available through July 2005, and all reported P values are two-sided and not adjusted for multiple testing.

RESULTS

\section{STUDY POPULATION}

Antiretroviral treatment was initiated in 304 women in the Mashi trial by October 2004. An additional 20 women ( 6 who received a single dose of nevirapine and 14 who received placebo) died before starting antiretroviral treatment. Of those who began treatment, 71 started ante partum and consequently did not receive a single peripartum dose of nevirapine or placebo, 8 started non-nevirapine-based antiretroviral treatment, and 7 were lost to follow-up or died before consenting to participate in the study. Therefore, 218 women are included in this analysis (112 previously randomly assigned to a single peripartum dose of nevirapine and 106 to placebo) (Fig. 1). 
Maternal characteristics of the 218 women enrolled were similar between the two groups (Table 1). Sixty women started antiretroviral treatment within 6 months after delivery, and 158 started 6 months or more after delivery. Measurements of plasma HIV-1 RNA levels taken at the 6-month visit were available for 109 women who had received a single dose of nevirapine (97.3\%) and for 96 who had received placebo $(90.6 \%)$ (Fig. 1). Measurements of HIV-1 RNA levels at 12 months were available for 94 women in the nevirapine group $(87.0 \%)$ and 88 women in the placebo group (88.9\%).

The primary end point of virologic failure by 6 months after the initiation of antiretroviral treatment occurred in 5 recipients of placebo $(5.0 \%)$ as compared with 20 recipients of a single dose of nevirapine (18.4\%, $\mathrm{P}=0.002$ ) (Table 2 and Fig. 2A). Significantly higher rates of virologic failure were seen in recipients of a single dose of nevirapine as compared with recipients of a single dose of placebo at 12 months $(\mathrm{P}=0.04)$ and 24 months $(\mathrm{P}=0.008)$ after the initiation of antiretroviral treatment (Table 2 and Fig. 2A), and in the analysis of time to virologic failure ( $\mathrm{P}=0.006)$.

The difference in outcomes depended on when antiretroviral treatment was initiated. In other words, for virologic failure there was an interaction $(\mathrm{P}=0.004)$ between exposure to a single dose of nevirapine or placebo and time to initiation of antiretroviral treatment. Among the 60 women starting antiretroviral treatment within 6 months after delivery, the estimated rates of virologic failure by the 6-month visit were 0 in the placebo group and $41.7 \%$ (10 women) in the nevirapine group ( $\mathrm{P}<0.001)$ (Table 2 and Fig. 2C). Similar significant differences were seen in the rates of virologic failure at 12 and 24 months (Table 2 and Fig. 2C). However, among the 158 women who started antiretroviral treatment 6 months or more after delivery, there were no significant differences in rates of virologic failure or time to virologic failure between the women in the nevirapine group and those in the placebo group at 6,12 , or 24 months after the initiation of antiretroviral treatment (Table 2 and Fig. 2D). Similar results were observed when we compared suppression of HIV-1 RNA levels to less than 400 copies per milliliter in the two groups of women at (rather than by) the visits at 6,12 , and 24 months after the initiation of antiretroviral treatment (data not shown).

Post hoc evaluation of our data suggested that
Figure 1 (facing page). Women (Panel A) and Infants (Panel B) Enrolled in the Study.

All women in the Mashi trial received zidovudine from 34 weeks' gestation through delivery. Assignment of infants to receive a single dose of nevirapine or placebo reflected maternal assignments. ART denotes antiretroviral treatment, and NVP nevirapine.

it was logical to divide the women into subgroups according to a 6-month cutoff point for the time of initiation of antiretroviral treatment post partum. When a 12-month cutoff point was used, the association between exposure to a single dose of nevirapine and virologic failure was somewhat attenuated (but still significant) in the women starting antiretroviral treatment less than 12 months post partum $(\mathrm{P}<0.001$ for all time points on antiretroviral treatment), with no significant differences in virologic failure among women starting 12 months or more post partum or among women starting between 6 and 12 months post partum ( $\mathrm{P} \geq 0.30$ for all comparisons).

There was a trend toward a higher rate of virologic failure in the subgroup of placebo recipients who started antiretroviral treatment 6 months or more post partum than in the subgroup of placebo recipients who started antiretroviral treatment less than 6 months post partum $(\mathrm{P}=0.05)$. This trend was lessened after controlling for HIV-1 RNA levels before antiretroviral treatment $(\mathrm{P}=0.11)$. These HIV-1 RNA levels were slightly higher in recipients of placebo who started antiretroviral treatment later post partum as compared with earlier (5.2 log copies per milliliter vs. $5.0 \log$ copies per milliliter, $\mathrm{P}=0.05$ ). Other characteristics, including CD4+ cell count, did not differ significantly between the two subgroups of placebo recipients. There were no significant differences between such subgroups of nevirapine recipients other than the timing of the initiation of antiretroviral treatment. Initiation of antiretroviral treatment within 6 months post partum remained significantly associated with virologic failure in nevirapine recipients, even after controlling for HIV-1 RNA levels and CD4+ cell count $(\mathrm{P}=0.004)$.

Ultrasensitive testing of plasma HIV-1 RNA was performed on all available samples from women who started antiretroviral treatment 6 months or more post partum and who had HIV-1 RNA levels of less than 400 copies per milliliter at 6 months of treatment; samples were available from 87 of 


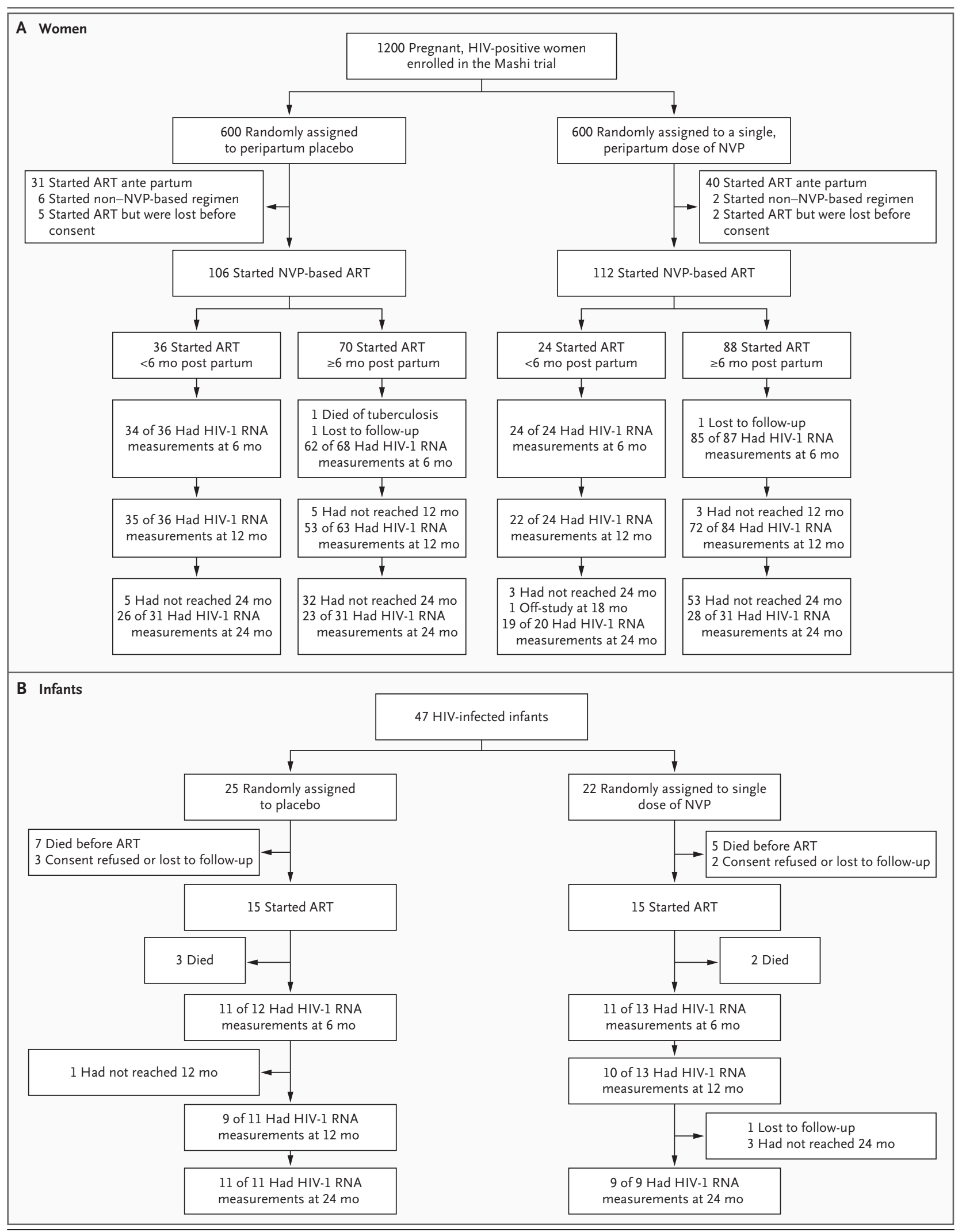

The New England Journal of Medicine 


\begin{tabular}{|c|c|c|c|}
\hline Maternal Characteristic & $\begin{array}{l}\text { Placebo Group } \\
\quad(N=106)\end{array}$ & $\begin{array}{l}\text { Group Receiving a Single } \\
\text { Dose of Nevirapine } \\
\text { ( } N=112)\end{array}$ & P Value \\
\hline \multicolumn{4}{|l|}{ Age at enrollment in Mashi trial — yr } \\
\hline Median & 27.5 & 27.5 & 0.64 \\
\hline Interquartile range & $24.2-32.3$ & $24.2-32.4$ & \\
\hline Randomly assigned to breast-feeding — no. (\%) & $52(49.1)$ & $55(49.1)$ & 0.99 \\
\hline $\begin{array}{l}\text { Self-reported ingestion of placebo or single dose of NVP } \\
\text { during labor - no. (\%) }\end{array}$ & $98(92.5)$ & $106(94.6)$ & 0.51 \\
\hline \multicolumn{4}{|l|}{ CD4+ count at enrollment (ante partum) - cells $/ \mathrm{mm}^{3}$} \\
\hline Median & 204 & 205 & 0.51 \\
\hline Interquartile range & $140-296$ & $137-267$ & \\
\hline \multicolumn{4}{|l|}{ CD4+ count before ART } \\
\hline Median - cells $/ \mathrm{mm}^{3}$ & 168 & 164 & 0.49 \\
\hline Interquartile range - cells $/ \mathrm{mm}^{3}$ & $112-198$ & $100-195$ & \\
\hline$<50$ cells $/ \mathrm{mm}^{3}$ —no. of women (\%) & $6(5.7)$ & $9(8.0)$ & \\
\hline \multicolumn{4}{|l|}{$\begin{array}{c}\text { Plasma HIV-1 RNA level at enrollment (ante partum) } \\
\quad \text { - log copies } / \mathrm{ml}\end{array}$} \\
\hline Median & 5.0 & 5.0 & 0.87 \\
\hline Interquartile range & $4.5-5.3$ & $4.5-5.4$ & \\
\hline \multicolumn{4}{|l|}{ Plasma HIV-I RNA level before ART — log copies $/ \mathrm{ml}$} \\
\hline Median & 5.2 & 5.1 & 0.87 \\
\hline Interquartile range & $4.7-5.6$ & $4.7-5.7$ & \\
\hline \multicolumn{4}{|l|}{ Time to initiation of ART after delivery } \\
\hline Median - mo & 10.1 & 12.3 & 0.58 \\
\hline $\begin{array}{l}\text { Within } 6 \text { mo after exposure to a single dose of NVP } \\
\text { or placebo - no. (\%) }\end{array}$ & $36(34.0)$ & $24(21.4)$ & \\
\hline \multicolumn{4}{|l|}{ Criteria for initiation of ART - no. (\%) } \\
\hline CD $4+$ count $<200$ cells $/ \mathrm{mm}^{3}$ & $98(92.5)$ & $104(92.9)$ & 0.81 \\
\hline AIDS-defining illness & $2(1.9)$ & $1(0.9)$ & \\
\hline Both & $6(5.7)$ & $7(6.3)$ & \\
\hline
\end{tabular}

143 women (60.8\%) who met these criteria (36 in the placebo group and 51 in the group receiving a single dose of nevirapine). Of these 87 women, $77.0 \%$ of those in the placebo group and $77.0 \%$ of those in the nevirapine group had HIV-1 RNA levels of less than 50 copies per milliliter at 6 months, suggesting no notable differences between the end points of less than 50 copies per milliliter and less than 400 copies per milliliter.

The median change in the maternal CD4+ cell count at 6 months of antiretroviral treatment was an increase of 122 cells per cubic millimeter. There were no significant differences in the CD4+ cell count (level or change) between the group receiving a single dose of nevirapine and the pla- cebo group, overall or within the timing subgroups - among women starting antiretroviral treatment within 6 months post partum, the median change in CD4+ cell count by the 6-month visit was an increase of 90 cells per cubic millimeter in the placebo group and an increase of 101 cells per cubic millimeter in the nevirapine group $(\mathrm{P}=0.86)$.

In univariate analyses of time to virologic failure, pre-antiretroviral-treatment HIV-1 RNA levels, CD4+ cell count, and status of exposure to nevirapine (whether a woman received placebo or a single dose of nevirapine) were significantly associated with virologic failure (Table 3); assigned feeding strategy, maternal age, and study clinic 


\begin{tabular}{|c|c|c|c|}
\hline Infant Characteristic & $\begin{array}{l}\text { Placebo Group } \\
\qquad(\mathrm{N}=15)\end{array}$ & $\begin{array}{l}\text { Group Receiving a Single } \\
\text { Dose of Nevirapine } \\
\qquad(\mathrm{N}=15)\end{array}$ & P Value \\
\hline \multicolumn{4}{|l|}{ Age at diagnosis of HIV-1 } \\
\hline Median - mo & 1.0 & 0.9 & 0.95 \\
\hline HIV-positive at birth - no. (\%) & $7(46.7)$ & $8(53.3)$ & \\
\hline HIV-positive at $\geq 6$ mo of age - no. (\%) & $2(13.3)$ & $3(20.0)$ & \\
\hline Randomly assigned to breast-feeding — no. (\%) & $10(66.7)$ & $13(86.7)$ & 0.39 \\
\hline \multicolumn{4}{|l|}{ CD4+ cell count before ART } \\
\hline Median - \% & 23.5 & 18.0 & 0.53 \\
\hline Missing CD4+ cell count - no. (\%) & $7(46.7)$ & $4(26.7)$ & \\
\hline \multicolumn{4}{|l|}{ Plasma HIV-1 RNA level before ART } \\
\hline Median - log copies/ml & 5.9 & 5.9 & 0.48 \\
\hline$<5.0$ log copies/ml — no. (\%) & $2(13.3)$ & 0 & \\
\hline Missing plasma HIV-1 RNA level — no. (\%) & $3(20.0)$ & $4(26.7)$ & \\
\hline \multicolumn{4}{|l|}{$\begin{array}{l}\text { Duration of zidovudine prophylaxis before } \\
\text { starting ART }\end{array}$} \\
\hline Median - mo & 1.1 & 2.0 & 0.68 \\
\hline$<1$ mo-no. (\%) & $5(33.3)$ & $3(20.0)$ & \\
\hline 1 to $<3 \mathrm{mo}-$ no. (\%) & $4(26.7)$ & $6(40.0)$ & \\
\hline 3 to 6 mo - no. (\%) & $6(40.0)$ & $6(40.0)$ & \\
\hline \multicolumn{4}{|l|}{ Age at initiation of ART } \\
\hline Median - mo & 8.38 & 8.51 & 0.95 \\
\hline Range - mo & $3.5-32.8$ & $2.1-33.4$ & \\
\hline$<6$ mo - no. (\%) & $3(20.0)$ & $5(33.3)$ & \\
\hline 6 to $<12$ mo - no. (\%) & $7(46.7)$ & $5(33.3)$ & \\
\hline 12 to < $18 \mathrm{mo}-$ no. (\%) & $3(20.0)$ & $3(20.0)$ & \\
\hline$\geq 18$ mo - no. (\%) & $2(13.3)$ & $2(13.3)$ & \\
\hline
\end{tabular}

* NVP denotes nevirapine, and ART antiretroviral treatment.

were not. In a multivariate model stratified according to the timing of the initiation of antiretroviral treatment, pre-antiretroviral-treatment CD4+ cell count (but not plasma HIV-1 RNA level) and receipt of a single dose of nevirapine remained significantly associated with time to virologic failure (Table 3).

When virologic failure was examined among only the 111 women who entered the Mashi trial with an antepartum CD4+ count of 200 cells or more per cubic millimeter, no significant difference was observed in rates of virologic failure between women who received a single dose of nevirapine and those who received placebo (with most of these women starting antiretroviral treatment 6 months or more post partum).

\section{MATERNAL GENOTYPE RESULTS}

Plasma samples from 16 of 20 women who received a single dose of nevirapine and who had virologic failure by 6 months of antiretroviral treatment were tested for HIV-1 resistance mutations before the start of antiretroviral treatment and at the time of virologic failure. Of these women, three $(18.8 \%)$ had no detectable nevirapine resistance mutations before antiretroviral treatment or at the time of virologic failure, one (6.2\%) had resistance at baseline but not at the time of failure, five (31.2\%) had no resistance at baseline but had resistance at the time of failure, and seven (43.8\%) had resistance both at baseline and at the time of failure. All 16 women were infected with HIV-1 subtype C (phylogenetic analysis of 368 


\begin{tabular}{|c|c|c|c|}
\hline Variable & Placebo Group & $\begin{array}{l}\text { Group Receiving } \\
\text { a Single Dose } \\
\text { of Nevirapine }\end{array}$ & P Value \\
\hline \multirow[t]{2}{*}{ All women } & $N=106$ & $N=112$ & \\
\hline & \multicolumn{2}{|c|}{ no. (\%) } & \\
\hline \multicolumn{4}{|l|}{ Mo after initiation of ART } \\
\hline 6 & $5(5.0)$ & $20(18.4)$ & 0.002 \\
\hline 12 & $9(9.6)$ & $21(19.7)$ & 0.04 \\
\hline 24 & $10(11.3)$ & $25(27.9)$ & 0.008 \\
\hline \multirow[t]{2}{*}{ Women who started ART $<6$ mo after delivery } & $N=36$ & $\mathrm{~N}=\mathbf{2 4}$ & \\
\hline & \multicolumn{2}{|c|}{ no. (\%) } & \\
\hline \multicolumn{4}{|l|}{ Mo after initiation of ART } \\
\hline 6 & 0 & $10(41.7)$ & $<0.001$ \\
\hline 12 & $1(2.9)$ & $11(45.8)$ & $<0.001$ \\
\hline 24 & $1(2.9)$ & $11(45.8)$ & $<0.001$ \\
\hline \multirow[t]{2}{*}{ Women who started ART $\geq 6$ mo after delivery } & $N=70$ & $\mathrm{~N}=88$ & \\
\hline & \multicolumn{2}{|c|}{ no. (\%) } & \\
\hline \multicolumn{4}{|l|}{ Mo after initiation of ART } \\
\hline 6 & $5(7.8)$ & $10(12.0)$ & 0.39 \\
\hline 12 & $8(13.8)$ & $10(12.0)$ & 0.76 \\
\hline 24 & $9(17.1)$ & $14(24.7)$ & 0.38 \\
\hline \multirow[t]{2}{*}{ All infants } & $\mathrm{N}=15$ & $N=15$ & \\
\hline & \multicolumn{2}{|c|}{ no. (\%) } & \\
\hline \multicolumn{4}{|l|}{ Mo after initiation of ART } \\
\hline 6 & $1(9.1)$ & $10(76.9)$ & $<0.001$ \\
\hline 12 & $1(9.1)$ & $10(76.9)$ & $<0.001$ \\
\hline 24 & $2(18.2)$ & $10(76.9)$ & $<0.001$ \\
\hline
\end{tabular}

* Rates of virologic failure were estimated with the use of Kaplan-Meier analyses.

maternal HIV-1 sequences in the Mashi trial revealed that all but 1 belonged to HIV-1C).

\section{NEVIRAPINE-BASED ANTIRETROVIRAL TREATMENT IN INFANTS}

Thirty infants born before August 12, 2002, started nevirapine-based antiretroviral treatment; 15 had received placebo and 15 had received a single dose of nevirapine (Fig. 1B). Baseline characteristics were similar in the two groups (Table 1). Three infants who had received placebo and two who had received a single dose of nevirapine died after initiation of antiretroviral treatment but before the 6-month visit; therefore, none of the five met the primary end point of virologic failure. By 6 months after the initiation of antiretroviral treatment, 1 infant in the placebo group (9.1\%) and 10 in the group receiving a single dose of nevirapine $(76.9 \%)$ had virologic failure $(\mathrm{P}<0.001)$ (Table 2 and Fig. 2B).

The distribution of and changes in the CD4+ percentages after the initiation of antiretroviral treatment in infants were significantly lower at most time points in infants who had received a single dose of nevirapine than in those who had received placebo. At 6 months after the initiation of antiretroviral treatment, the median $\mathrm{CD} 4+$ percentages were $23.0 \%$ in infants who had received a single dose of nevirapine and $31.0 \%$ in those who had received placebo $(\mathrm{P}=0.04)$, with median increases in CD4+ cells of 5.8 percentage points and 13.0 percentage points, respectively $(\mathrm{P}=0.30)$. The median $\mathrm{CD} 4+$ percentages at 12 months after the initiation of antiretroviral treatment were 


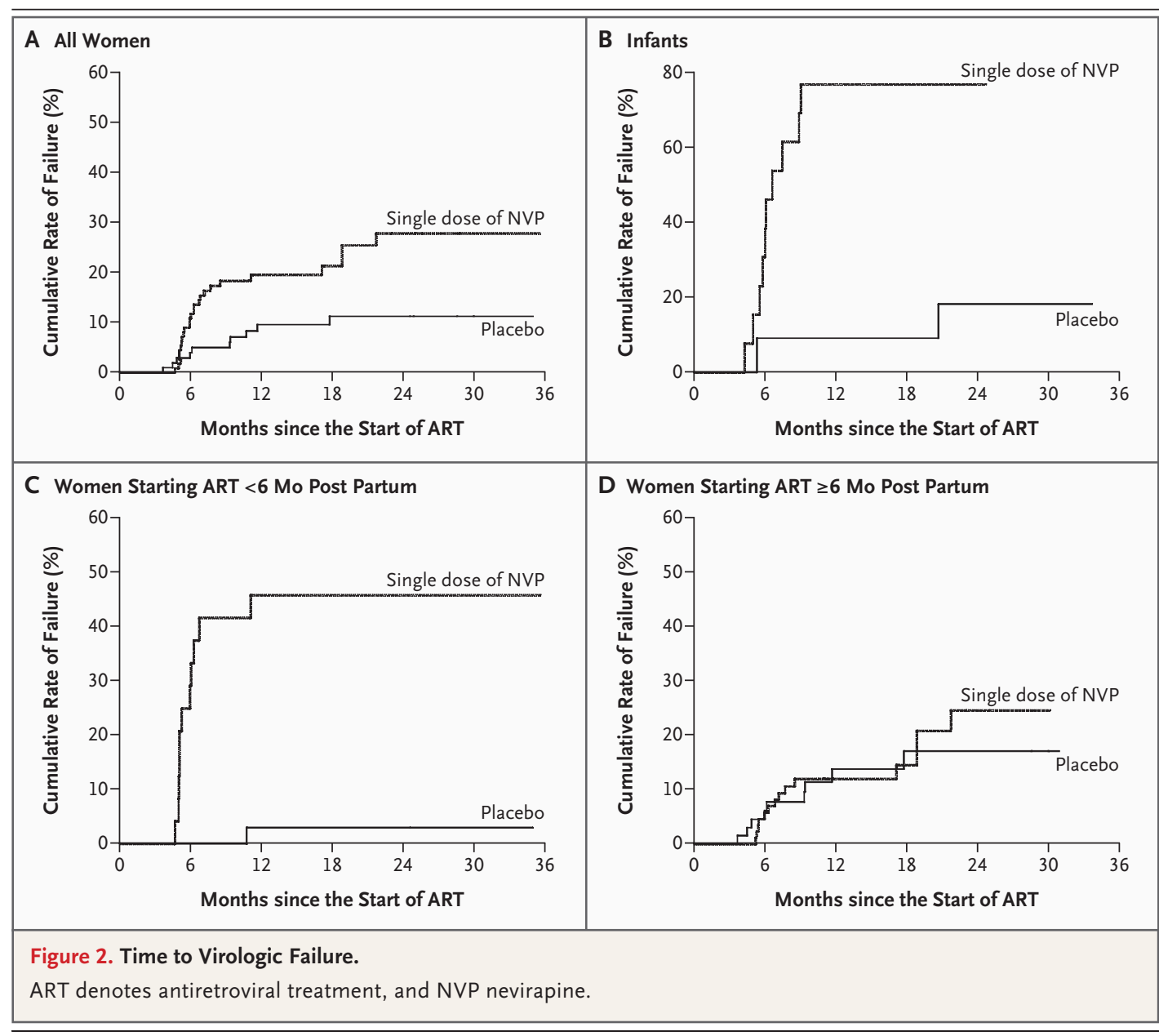

$28.6 \%$ (5.2\% increase) in the group receiving a single dose of nevirapine and $37.1 \%(22.0 \%$ increase) in the placebo group $(\mathrm{P}=0.01$ for both comparisons).

\section{DISCUSSION}

Women who had received a single dose of nevirapine had significantly higher rates of virologic failure on subsequent nevirapine-based antiretroviral treatment than did women who had received placebo. This apparently deleterious effect of a single dose of nevirapine was concentrated in women who initiated antiretroviral treatment within 6 months after receiving a single dose of nevirapine. We did not find that a previous single dose of nevirapine compromised the efficacy of subsequent nevirapine-based antiretroviral treatment in women who started antiretroviral treatment 6 months or more after delivery. Among the 30 HIV-infected infants, a single dose of nevira- pine (one each to mother and infant) as compared with placebo was associated with significantly higher rates of virologic failure and smaller CD4+ percentage increases in response to subsequent nevirapine-based antiretroviral treatment.

These data suggest that women who start nevirapine-based antiretroviral treatment later after receiving a single dose of nevirapine may have rates of virologic suppression as high as those among women who have not previously received a single dose of nevirapine. Jourdain et al. did not find that rates of virologic failure varied according to the timing of the initiation of antiretroviral treatment after a single dose of nevirapine. ${ }^{14}$ However, the ability of the Thai study to detect interaction between exposure to a single dose of nevirapine and the timing of antiretroviral-treatment initiation was limited, because only 48 women did not receive a single dose of nevirapine (and this group started antiretroviral treatment significantly later than the women who 


\begin{tabular}{|c|c|c|}
\hline Factor & $\begin{array}{c}\text { Univariate } \\
\text { Hazard Ratio }(95 \% \mathrm{Cl}) \dagger\end{array}$ & $\begin{array}{c}\text { Multivariate } \\
\text { Hazard Ratio }(95 \% \mathrm{Cl}) \%\end{array}$ \\
\hline \multicolumn{3}{|l|}{ All women } \\
\hline \multicolumn{3}{|l|}{ HIV RNA level before ART } \\
\hline Per 1 log increase & $1.9(1.0-3.4)$ & $1.9(1.0-3.9)$ \\
\hline$\geq 5.0 \mathrm{log}$ copies $/ \mathrm{ml}$ versus $<5.0 \mathrm{log}$ copies $/ \mathrm{ml}$ & $1.6(0.8-3.3)$ & $1.8(0.9-3.8)$ \\
\hline \multicolumn{3}{|l|}{ CD4+ count before ART } \\
\hline Per increase of 10 cells $/ \mathrm{mm}^{3}$ & $0.9(0.9-1.0)$ & $0.9(0.9-1.0)$ \\
\hline$<200$ cells $/ \mathrm{mm}^{3}$ versus $\geq 200$ cells $/ \mathrm{mm}^{3}$ & $2.5(0.8-8.2)$ & $2.9(0.9-9.4)$ \\
\hline Single-dose NVP versus placebo & $2.7(1.3-5.8)$ & \\
\hline Controlling for continuous covariates & & $4.9(1.8-13.3)$ \\
\hline Controlling for covariate subgroups & & $2.9(1.4-6.3)$ \\
\hline \multicolumn{3}{|l|}{ Women starting ART $<6$ mo post partum } \\
\hline \multicolumn{3}{|l|}{ HIV RNA level before ART } \\
\hline Per 1 log increase & $2.6(0.9-7.1)$ & $4.3(1.1-16.8)$ \\
\hline$\geq 5.0 \mathrm{log}$ copies $/ \mathrm{ml}$ versus $<5.0 \mathrm{log}$ copies $/ \mathrm{ml}$ & $4.4(1.0-20.1)$ & $6.3(1.3-29.1)$ \\
\hline \multicolumn{3}{|l|}{ CD4+ count before ART } \\
\hline Per increase of 10 cells $/ \mathrm{mm}^{3}$ & $0.8(0.5-1.2)$ & $0.95(0.9-1.0)$ \\
\hline$<200$ cells $/ \mathrm{mm}^{3}$ versus $\geq 200$ cells $/ \mathrm{mm}^{3}$ & $3.4(0.4-26.7)$ & $5.5(0.7-43.1)$ \\
\hline Single-dose NVP versus placebo & $22(2.8-169.0)$ & \\
\hline Controlling for continuous covariates & & Large, unstable \\
\hline Controlling for covariate subgroups & & $27.9(3.5-219.0)$ \\
\hline \multicolumn{3}{|l|}{ Women starting ART $\geq 6$ mo post partum } \\
\hline \multicolumn{3}{|l|}{ HIV RNA level before ART } \\
\hline Per 1 log increase & $1.5(0.7-3.2)$ & $1.3(0.6-3.0)$ \\
\hline$\geq 5.0 \mathrm{log}$ copies $/ \mathrm{ml}$ versus $<5.0 \mathrm{log}$ copies $/ \mathrm{ml}$ & $1.0(0.4-2.4)$ & $1.0(0.4-2.5)$ \\
\hline \multicolumn{3}{|l|}{ CD4+ count before ART } \\
\hline Per increase of 10 cells $/ \mathrm{mm}^{3}$ & $0.9(0.9-1.0)$ & $0.9(0.9-1.0)$ \\
\hline$<200$ cells $/ \mathrm{mm}^{3}$ versus $\geq 200$ cells $/ \mathrm{mm}^{3}$ & $2.1(0.5-9.0)$ & $2.1(0.5-2.7)$ \\
\hline Single-dose NVP versus placebo & $1.2(0.5-2.8)$ & \\
\hline Controlling for continuous covariates & & $1.9(0.7-5.4)$ \\
\hline Controlling for covariate subgroups & & $1.2(0.5-2.8)$ \\
\hline
\end{tabular}

$* \mathrm{Cl}$ denotes confidence interval, ART antiretroviral therapy, and NVP nevirapine.

$\dagger$ The following factors were not associated with time to virologic failure in univariate analyses: study site $(P=0.66)$, maternal age $(P=0.84)$, assigned infant-feeding strategy $(P=0.54)$, and plasma HIV-l RNA level at enrollment $(P=0.09)$. $¥$ The multivariate hazard ratios were adjusted for HIV RNA levels before ART, CD4+ cell count before ART, and receipt of a single dose of nevirapine or placebo.

received a single dose of nevirapine). ${ }^{14}$ Recent ab- and nevirapine-unexposed women with confoundstracts also suggest that virologic ${ }^{17}$ and immuno$\operatorname{logic}^{18}$ outcomes of nevirapine-based antiretroviral treatment in a program setting are similar in women who received a single dose of nevirapine 9 months or more previously and in those who did not receive a single dose of nevirapine. However, these studies enrolled nevirapine-exposed and nevirapine-unexposed women with confound-
ing differences in key prognostic factors - important limiting biases that are likely to affect any study enrolling women who have not been contemporaneously randomly assigned to receive or not receive a single peripartum dose of nevirapine.

Our finding that virologic failure after expo- 
sure to a single dose of nevirapine is more likely to occur when postpartum antiretroviral treatment is started earlier, as opposed to later, is consistent with the observation that nevirapine resistance mutations fade from detection with time, although mutant strains are still detectable in some women and infants 12 to 24 months after exposure to a single dose of nevirapine when highly sensitive resistance assays are used..$^{19-21}$ Mutations archived after exposure to a single dose of nevirapine may reemerge with a longer duration of nevirapine-based antiretroviral treatment. However, the short duration of exposure to a single dose of nevirapine may limit the number of archived mutations in viral reservoirs. Minor nevirapine-resistant variants archived in cellular DNA were found to decline from $52 \%$ at 6 weeks to $4 \%$ at 12 months post partum in one South African study. ${ }^{19}$ Additional follow-up from the Thai study ${ }^{14}$ showed that among women with virologic suppression after 6 months of antiretroviral treatment who received a single dose of nevirapine or placebo, no differences in treatment response emerged with follow-up through 18 months. ${ }^{22}$ We are continuing to follow (and enroll participants in) the Mashi cohort of women who are receiving antiretroviral treatment, to evaluate the longevity of virologic suppression in a larger number of recipients of a single dose of nevirapine or placebo who started antiretroviral treatment 6 months or more post partum. This additional follow-up is important, since data on 24-month HIV-1 RNA levels were available for only 96 women.

We found trends toward higher rates of virologic failure and higher pretreatment HIV-1 RNA levels in placebo-exposed women who started antiretroviral treatment later, as compared with earlier, post partum; some women starting treatment 6 months or more post partum may have had progression to more advanced HIV disease by the time antiretroviral treatment became available. However, because women who had received a single dose of nevirapine or placebo started antiretroviral treatment at similar times post partum and at similar disease stages, temporal differences should apply in a similar way to both women who had received a single dose of nevirapine and those who had received placebo.

The difference in treatment response among infants was large. However, this was a very small group that started antiretroviral treatment at a relatively young age and that also received perinatal zidovudine. Although our findings raise concern about the efficacy of nevirapine-based antiretroviral treatment in infants receiving a single dose of nevirapine, pediatric data from other studies will be very important.

Rates of detectable nevirapine resistance mutations seem to be higher in women and infants when a single dose of nevirapine is the only drug used for the prevention of mother-to-child transmission of HIV-1 ${ }^{13,23,24}$; it is possible that differences in treatment outcome may be worse after exposure to only a single dose of nevirapine (as compared with exposure to a single dose of nevirapine and zidovudine, as in this study). A regimen of a short course of zidovudine plus a single dose of nevirapine (similar to the Mashi trial regimen) is now used to prevent mother-to-child transmission of HIV-1 in many developing nations, in accordance with WHO guidelines. ${ }^{1}$

HIV-1 subtype C is the most prevalent HIV-1 subtype globally, ${ }^{25}$ predominating in southern Africa (including Botswana) and much of Asia and accounting for $99.7 \%$ of tested HIV-1 isolates from participants in the Mashi trial. Nevirapine resistance mutations after a single dose of nevirapine may emerge more frequently with HIV-1 subtype C than with other HIV-1 subtypes. ${ }^{9,26}$ Therefore, women with non-C subtypes who start antiretroviral treatment 6 months or more after receiving a single dose of nevirapine may have therapeutic outcomes that are at least as favorable as those observed in this study. Although our results are quite broadly applicable, data from populations infected with other HIV-1 subtypes or data resulting from the use of other regimens containing a single dose of nevirapine for the prevention of mother-to-child transmission of HIV-1 would provide additional insights.

In summary, this study shows that women who start nevirapine-based antiretroviral treatment 6 months or more after receiving a single dose of nevirapine have rates of virologic suppression similar to those among women who are not exposed to nevirapine, and that nevirapinebased treatment may therefore be considered for such women. However, it will be important to evaluate virologic responses after at least 24 months of follow-up of this cohort. Because it may not be safe to delay the initiation of antiretroviral treatment for 6 months or more post partum in women with advanced AIDS, initiation 
of non-nevirapine-based regimens should be considered for women starting antiretroviral treatment within 6 months after receiving a single dose of nevirapine. Furthermore, exposure to a single dose of nevirapine followed by nevirapinebased antiretroviral treatment was associated with high rates of virologic failure in the small group of infants that we studied.

Every effort should be made to provide antepartum combination antiretroviral treatment to women who qualify for antiretroviral treatment for their own health, since these are the women at highest risk for AIDS-related complications or death, for transmitting HIV to their infants, and for the development of nevirapine resistance after a single dose of nevirapine. However, singledose nevirapine (with or without additional antiretroviral agents) remains an important component of the global strategy for the prevention of mother-to-child transmission of HIV-1 in women who do not yet qualify for antiretroviral treatment and for areas where treatment is not available. Our finding that women with more remote exposure to a single dose of nevirapine have high rates of virologic suppression in response to nevirapinebased antiretroviral treatment is reassuring for the many women who have received a single dose of nevirapine and to those who will receive it.

Supported by grants from the National Institute of Child Health and Human Development (R01 HD44391 and R01 HD37793) and the Fogarty International Center (D43 TW00004), by UNICEF, by Boehringer Ingelheim (which provided the single doses of nevirapine and placebo for the parent Mashi Study), and by GlaxoSmithKline (which provided zidovudine prophylaxis for the parent Mashi Study).

Drs. Thior, Makhema, and Novitsky and Mr. Widenfelt report receiving grant support from Secure the Future Foundation, which was established by Bristol-Myers Squibb. No other potential conflict of interest relevant to this article was reported.

Any opinions, findings, and conclusions or recommendations expressed in this publication are those of the authors and do not necessarily reflect the views of the sponsoring agencies and organizations. Sponsors were not involved in the collection or analysis of data or in the preparation of this report.

We thank the patients participating in the Mashi Study; the Mashi Study team; the Botswana Ministry of Health for providing the antiretroviral drugs and the laboratory-test monitoring for women and infants receiving highly active antiretroviral therapy; the administration and staff at the Scottish Livingstone, Deborah Retief Memorial, Athlone, and Princess Marina Hospitals; the staff at the referring health clinics; the Botswana Central Medical Store; and the following persons: M.P. Holme, P. Mazonde, S. El-Halabi, L. Mofenson, R. Madison, J. Leidner, G. Sebetso, T. Ndung'u, T. Masoloko, K. Onyait, R. Leepo, K. Mburu, S. Moyo, O. Nthase, M.F. McLane, and E. Garmey.

\section{APPENDIX}

The Mashi Study team included the following persons: Molepolole site - C. Anude, J. Chanda, L. Makori, J. Banno Moorad, T.A. Modise, T. Moyo, D. Arbi, M. Malamba, K. Koloi, L. Dube, T. Mmolotsi, S. Babitseng, D. Mere; Mochudi site - J. Boyle, J. Magetse, V. Modikwa, T. Sekoto, L. Garebatho, M. Tsuro, M. Sesinyi, K. Kelebalekgosi; Lobatse site - Z. Tedla, G. Mayondi, N. Makubate, K. Sebinang, L. Tsalaile, B. Tsule, I. Thebeetsile, J. Setswalo, I. Leteane, O. Makgabana; Gaborone site - M. Mogodi, I. Hove, A. Owor, T. Kakhu, P. Ramalepa, J. Lubinda, S. Ndebele, F. Modise, C. Bohule, M. Ntshimane.

REFERENCES

1. Antiretroviral drugs for treating preg nant women and preventing HIV infection in infants in resource-limited settings: towards universal access: recommendations for a public health approach. Geneva World Health Organization, 2006.

2. Antiretroviral therapy for HIV infection in adults and adolescents in resourcelimited settings: towards universal access recommendations for a public health approach. Geneva: World Health Organization, 2006

3. Guay LA, Musoke P, Fleming T, et al Intrapartum and neonatal single-dose nevirapine compared with zidovudine for prevention of mother-to-child transmission of HIV-1 in Kampala, Uganda: HIVNET 012 randomised trial. Lancet 1999;354: 795-802.

4. Jackson JB, Musoke P, Fleming T, et al. Intrapartum and neonatal single-dose nevirapine compared with zidovudine for prevention of mother-to-child transmission of HIV-1 in Kampala, Uganda: 18-month follow-up of the HIVNET 012 randomised trial. Lancet 2003;362:859-68.
5. Viramune donation programme. (Accessed December 14, 2006, at http://www. boehringeringelheim.com/wecare/en/ subpages/our_society_1.htm.)

6. Eshleman SH, Mracna M, Guay LA, et al. Selection and fading of resistance mutations in women and infants receiving nevirapine to prevent HIV-1 vertical transmission (HIVNET 012). AIDS 2001;15 1951-7.

7. Jackson JB, Becker-Pergola G, Guay $\mathrm{LA}$, et al. Identification of the $\mathrm{K} 103 \mathrm{~N}$ resistance mutation in Ugandan women receiving nevirapine to prevent HIV-1 vertical transmission. AIDS 2000;14:F111-F115.

8. Lee EJ, Kantor R, Zijenah L, et al. Breast-milk shedding of drug-resistant HIV-1 subtype C in women exposed to single-dose nevirapine. J Infect Dis 2005; 192:1260-4.

9. Eshleman SH, Hoover DR, Chen S, et al. Nevirapine (NVP) resistance in women with HIV-1 subtype C, compared with subtypes $A$ and D, after the administration of single-dose NVP. J Infect Dis 2005;192: 30-6.
10. Shapiro RL, Thior I, Gilbert PB, et al. Maternal single-dose nevirapine versus placebo as part of an antiretroviral strategy to prevent mother-to-child HIV transmission in Botswana. AIDS 2006;20: 1281-8.

11. Eshleman SH, Hoover DR, Chen S, et al. Resistance after single-dose nevirapine prophylaxis emerges in a high proportion of Malawian newborns. AIDS 2005;19: 2167-75.

12. Pillay CCN, Gray G, Chezzi C, et al. Nevirapine resistance mutations among HIV-1 infected infants following single dose nevirapine. In: Program and abstracts of the XVth International AIDS Conference, Bangkok, Thailand, July 11-16, 2004. abstract.

13. Eshleman SH, Hoover DR, Hudelson $\mathrm{SE}$, et al. Development of nevirapine resistance in infants is reduced by use of infant-only single-dose nevirapine plus zidovudine postexposure prophylaxis for the prevention of mother-to-child transmission of HIV-1. J Infect Dis 2006;193: 479-81. 
14. Jourdain G, Ngo-Giang-Huong N, Le Coeur S, et al. Intrapartum exposure to nevirapine and subsequent maternal responses to nevirapine-based antiretroviral therapy. N Engl J Med 2004;351:229-40.

15. Thior I, Lockman S, Smeaton LM, et al. Breastfeeding plus infant zidovudine prophylaxis for 6 months vs formula feeding plus infant zidovudine for 1 month to reduce mother-to-child transmission in Botswana: a randomized trial: the Mash Study. JAMA 2006;296:794-805.

16. Stanford University HIV drug resistance database. (Accessed December 14 2006, at http://hivdb.stanford.edu.)

17. Coovadia H, Marais B, Abrams E, et al. Virologic responses to NNRTI treatment among women who took single-dose nevirapine 18 to 36 months earlier. In: Program and abstracts of the 13th Conference on Retroviruses and Opportunistic Infections, Denver, February 5-8, 2006. abstract.

18. Bedikou G, Viho I, Towne-Gold B, et al. 6-Month immunological response with HAART containing nevirapine in HIV in fected women post exposure to single dose of Nevirapine for PMTCT: the MTCT-Plus
Initiative in Abidjan, Cote d'Iviore (20032005). In: Program and abstracts of the 3rd IS Conference on HIV Pathogenesis and Treatment, Rio de Janiero, July 24-27, 2005. abstract.

19. Loubser S, Balfe P, Sherman G, Hammer S, Kuhn L, Morris L. Decay of K103N mutants in cellular DNA and plasma RNA after single-dose nevirapine to reduce mother-to-child HIV transmission. AIDS 2006;20:995-1002.

20. Flys T, Nissley DV, Claasen CW, et al. Sensitive drug-resistance assays revea long-term persistence of HIV-1 variant with the K103N nevirapine (NVP) resistance mutation in some women and infants after the administration of singledose NVP: HIVNET 012. J Infect Dis 2005; 192:24-9.

21. Palmer S, Boltz V, Martinson N, et al. Persistence of nevirapine-resistant HIV-1 in women after single-dose nevirapine therapy for prevention of maternal-to-fetal HIV-1 transmission. Proc Natl Acad Sci U S A 2006;103:7094-9.

22. Lallemant M. Response to therapy after prior exposure to nevirapine. In: Program and abstracts of the 3rd IAS Conference on HIV Pathogenesis and Treatment, Rio de Janeiro, July 24-27, 2005. abstract.

23. Chaix ML, Ekouevi DK, Rouet F, et al. Low risk of nevirapine resistance mutations in the prevention of mother-to-child transmission of HIV-1: Agence Nationale de Recherches sur le SIDA Ditrame Plus, Abidjan, Cote d'Ivoire. J Infect Dis 2006; 193:482-7.

24. McIntyre JA, Martinson N, Gray GE, et al. Addition of short course Combivir to single dose Viramune for the prevention of mother to child transmission of HIV-1 can significantly decrease the subsequent development of maternal and paediatric NNRTI-resistant virus. In: Program and abstracts of the 3rd IAS Conference on HIV Pathogenesis and Treatment, Rio de Janeiro, July 24-27, 2005. abstract.

25. McCutchan FE. Global epidemiology of HIV. J Med Virol 2006;78:Suppl 1:S7-S12. 26. Flys TS, Chen S, Jones DC, et al. Quantitative analysis of HIV-1 variants with the K103N resistance mutation after singledose nevirapine in women with HIV-1 subtypes A, C, and D. J Acquir Immune Defic Syndr 2006;42:610-3.

Copyright @ 2007 Massachusetts Medical Society.

FULL TEXT OF ALL JOURNAL ARTICLES ON THE WORLD WIDE WEB

Access to the complete text of the Journal on the Internet is free to all subscribers. To use this Web site, subscribers should go to the Journal's home page (www.nejm.org) and register by entering their names and subscriber numbers as they appear on their mailing labels. After this one-time registration, subscribers can use their passwords to log on for electronic access to the entire Journal from any computer that is connected to the Internet. Features include a library of all issues since January 1993 and abstracts since January 1975, a full-text search capacity, and a personal archive for saving articles and search results of interest. All articles can be printed in a format that is virtually identical to that of the typeset pages. Beginning 6 months after publication, the full text of all Original Articles and Special Articles is available free to nonsubscribers who have completed a brief registration. 